\title{
ПРИМЕНЕНИЕ МЕТОДА ТИПОЛОГИЗАЦИИ ПРИ РАЗРАБОТКЕ ТИПОЛОГИИ СЕЛЬСКИХ ПОСЕЛЕНИЙ ДЛЯ ОПРЕДЕЛЕНИЯ ДИФФЕРЕНЦИРОВАННЫХ ТРЕБОВАНИЙ К АРХИТЕКТУРНОМУ БЛАГОУСТРОЙСТВУ ИХ СЕЛИТЕБНЫХ ТЕРРИТОРИЙ
}

\author{
Р. А. Другомилов ${ }^{1}$
}

${ }^{1}$ К. арх., доцент кафредры сельского строительства и обустройства территорий БГСХА, Горки, Беларусь

\begin{abstract}
Реферат
В статье описывается применение метода типологизации при разработке типологии сельских поселений для определения дифференцированных требований к архитектурному благоустройству их селитебных территорий. Определены ведущие типологические признаки, определяющие характерные особенности сельских поселений и оказывающие непосредственное влияние на формирование архитектурного благоустройства селитебных территорий, проведено сопоставление совокупности выделенных типологических признаков объектов исследования на основании построенной плоскостной сводной типологической матрицы, в результате чего выделено восемь типов сельских поселений, отражающих возможные совокупности ведущих типологических признаков, которые оказывают влияние на архитектурное благоустройство селитебных территорий.
\end{abstract}

Ключевые слова: метод типологизации, архитектурное благоустройство, сельские поселения, селитебные территории, типология.

\section{APPLICATION OF THE TYPOLOGIZATION METHOD IN DEVELOPING THE TYPOLOGY OF RURAL SETTLEMENTS TO DETERMINE DIFFERENTIATED REQUIREMENTS FOR THE TERRITORY ARCHITECTURAL ACCOMPLISHMENT OF THEIR RESIDENTIAL TERRITORIES}

Abstract

\section{R. A. Drugomilov}

The article describes the application of the typologization method in develoing the typology of rural settlements to determine differentiated requirements for the territory architectural accomplishment of their residential territories. The leading typological features that determine the characteristic features of rural settlements and have a direct impact on the formation of territory architectural accomplishment of residential territories are identified a comparison of the set of selected typological features of research objects is made on the basis of a planar consolidated typological matrix, as a result of which eight types of rural settlements are identified, reflecting possible sets of leading typological features that affect the territory architectural accomplishment of residential territories.

Keywords: typologization method, territory architectural accomplishment, rural settlements, residential territories, typology.

\section{Введение}

Метод типологизации - достаточно распространенный метод научного познания в разнообразных исследованиях в области архитектуры, основанный на принципах типологии. Этот метод направлен на разбиение некой совокупности объектов исследования на упорядоченные группы, обладающие определенной совокупностью признаков и свойств, с помощью идеализированной модели.

Этот метод был применен и в процессе изучения на протяжении нескольких последних лет архитектурного благоустройства селитебных территорий сельских поселений Могилевской области, где важной задачей стало определение тех особенностей объектов исследований (сельских поселений), которые, наряду с условиями формирования архитектурного благоустройства сельских поселений [1], оказывают существенное влияние на формирование архитектурного благоустройства в пределах жилых и общественных территорий. Без этого рекомендации по дальнейшему развитию архитектурного благоустройства были бы слишком обобщенными для всех сельских поселений в целом и не отражали бы в необходимой мере влияние не только их особенных черт, но и возможных их сочетаний. Кроме того, некоторые сельские поселения, обладающие определенными свойствами, могли бы оказаться попросту не замечены и быть ошибочно не включены в генеральную совокупность ввиду своей малочисленности.

Разработка типологии сельских поселений для определения дифференцированных требований к архитектурному благоустройству их селитебных территорий на основе метода типологизации

Для достижения достоверного результата в первую очередь были выявлены ведущие типологические признаки объектов исследования, оказывающие непосредственное влияние на архитектурное благоустройство селитебных территорий сельских поселений. На основании анализа различных информационных источников, проектных материалов, а также результатов натурных обследований в ходе экспедиционных поездок по сельских поселениям Могилевской области к таким признакам были отнесены следующие: роль в системе расселения, расположение относительно крупного города, численность населения, расположение относительно наземных транспортных коридоров. Рассмотрим каждый из признаков в отдельности.

Роль в системе расселения. По роли в системе расселения сельские поселения можно разделить на опорные центры сельского расселения (к ним относятся центральные усадьбы сельских советов, а также другие большие и крупные сельские поселения, для которых характерна относительно стабильная численность населения, выгодное географическое положение, развитая социальная и производственная инфраструктура, что обеспечивает возможность удовлетворения потребности их населения и населения ближайших деревень в различных социальных услугах в сфере образовании, трудоустройства, здравоохранения, торговли, общественного питания, культуры и др.) и рядовые сельские поселения (сюда относятся остальные сельские поселения, включающие преимущественно жилую застройку и не обладающие таким благоприятным сочетанием характеристик, свойственным первой группе). Влияние, оказываемое на формирование системы архитектурного благоустройства сельских поселений, обусловливается возможным наличием в опорных центрах сельского расселения наиболее полного перечня общественных объектов, благоустройство территорий каждого из которых имеет свои особенности, а также более высокими требованиями 
Вестник Брестского государственного технического университета. 2021

(продиктованными в свое время в Государственной программе возрождения и развития села на 2005-2010 годы и в определенной степени достигнутыми по ее завершении) к уровню благоустройства по сравнению с рядовыми сельскими поселениями.

Расположение относительно крупного города. В архитектурной среде сельских поселений, преимущественно крупных, расположенных в пригородной зоне крупного города (в Могилевской области таким городом является областной центр - г. Могилев), соответствующей 40-минутной транспортной доступности [2, пункт 11.2.3], существуют значительные отличия от сельских поселений, расположенных на отдалении от крупного города, выражающиеся, в том числе, и в более характерном для городских поселений уровне архитектурного благоустройства. Это обусловлено устоявшейся маятниковой миграцией, связанной с трудовой, рекреационной и др. деятельностью населения (например, часть трудоспособного населения может работать в крупном городе, ежедневно по будням выезжая из сельского поселения и возвращаясь в него; в выходные, наоборот, горожане могут совершать загородные поездки для отдыха) и, соответственно, необходимостью максимального устранения различий между городом и деревней за счет активного применения современных строительных материалов, конструкций, изделий, элементов архитектурного благоустройства и др., обеспечения горожанам возможности качественного отдыха в сельских поселениях путем создания рекреационных территорий - прибрежных зон отдыха, парков и др. Поэтому логично разделять сельские поселения на две группы в зависимости от расположения по отношению к крупному городу: сельские поселения, расположенные в пригородной зоне крупного города и вне ее.

Численность населения. Численность населения сельских поселений непосредственно связана с их ролью в системе расселения: большинство крупных (с населением более 1000 человек) сельских поселений являются опорными центрами сельского расселения с максимально возможным составом общественных объектов, малые (до 100 человек) сельские поселения в основном являются рядовыми с единичными общественными объектами или их полным отсутствием. Для больших (500...1000 человек) и крупных сельских поселений также характерно наличие секционной безусадебной жилой застройки, благоустройство которой имеет свои особенности по сравнению с усадебной, наличие которой характерно для всех типов сельских поселений. Да и в целом уровень и характер архитектурного благоустройства сельских поселениях с различной численностью населения варьируется - от организованного благоустройства в крупных и больших опорных центрах сельского расселения, приближенного по своему уровню к городскому, до самодеятельного и стихийного благоустройства в средних (100...500 человек) и малых рядовых сельских поселениях, сохраняющих традиционный колорит сельской среды. Поэтому учет численности населения позволит обеспечить логичное сохранение сформировавшихся тенденций в развитии архитектурного благоустройства за счет выбора подходящих приемов преобразования среды, а также более рациональный подход к определению необходимого состава элементов архитектурного благоустройства, исходя из условия необходимости обеспечения максимально комфортных условий жизнедеятельности для наибольшего числа жителей.

Расположение относительно наземных транспортных коридоров. Сельские поселения могут пересекаться автомобильными и железными дорогами, что диктует необходимость обеспечения безопасности передвижения автомобилистов, пешеходов, велосипедистов в пределах сельских поселений (устройство тротуаров, пешеходных переходов, ограждений, технических средств организации дорожного движения, павильонов на остановочных пунктах общественного транспорта и др.), а главная улица, являясь частью автомобильной дороги, в таком случае становится своеобразным лицом сельского поселения, появляется необходимость создания эстетически-выразительного облика сельского поселения для проезжающих автомобилистов и пассажиров. Также появляется возможность устройства придорожных мест отдыха в пределах сельского поселения, в том числе и совмещения их с сельскими торговыми объектами и объектами общественного питания. В то же время натурные обследования показали, что значительно большее влияние на внешний облик пересекаемых сельских поселений оказывают республиканские автомобильные дороги общего пользования по сравнению с местными автодорогами общего пользования и внутрихозяйственными дорогами ввиду больших интенсивности движения транспортных средств, объема перевозок пассажиров и др. Поэтому рассматривать такие сельские поселения необходимо отдельно (при пересечении сельского поселения автомобильными дорогами разных типов, объект исследования необходимо причислять к группе сельских поселений, пересекаемых автомобильной дорогой более высокого ранга). Также в переделах территории сельских поселений могут размещаться железнодорожные станции и остановочные пункты пригородного железнодорожного транспорта, что определяет необходимость благоустройства территорий этих объектов.

После определения ведущих типологических признаков объектов исследования, следующим этапом разработки типологии сельских поселений, необходимой для определения дифференцированных требований к архитектурному благоустройству их селитебных территорий, стало составление одной плоскостной (в соответствии с количеством признаков, которых было выявлено четыре) типологической матрицы, что позволило обнаружить зависимость между отдельными типологическими характеристиками объектов.

Предварительный анализ объектов исследования (3033 сельских поселения Могилевской области в соответствии с заранее составленным перечнем), опирающийся на выявленные типологические признаки, показал, что подавляющее большинство сельских поселений $(93 \%)$ является рядовыми сельскими поселениями, большая часть из которых относятся к средним и малым по численности населения сельским поселениям. Поэтому из общего числа средних и малых рядовых сельских поселений, ввиду их многочисленности и схожести в организации архитектурного благоустройства, для целей настоящего исследования отобрано 70. Рядовых сельских поселений с численностью населения более 500 человек в регионе насчитывается около 30, в типологическую матрицу вошли шесть из них. Количество опорных центров сельского расселения в Могилевской области составляет 202, для целей исследования отобрано 95 таких объектов. Таким образом, в качестве генеральной совокупности принят 171 объект исследования.

Анализ распределения объектов исследования в типологической матрице (рисунок 1) показал следующее. В генеральной совокупности преобладают сельские поселения, расположенные вне пригородной зоны крупного города - 151 объект исследования (88 \% от общего количества объектов принятой генеральной совокупности). В пригородной зоне крупного города выявлено 20 сельских поселений - 9 опорных центров сельского расселения и 11 рядовых сельских поселений. По численности населения наиболее представительной группой являются сельские поселения с количеством жителей менее 500 (112 единиц или $65 \%$ ), из них 42 опорных центра сельского расселения и 70 рядовых сельских поселений. Больших сельских поселений насчитывается 44 единицы или $26 \%$ (38 опорных центров сельского расселения и 6 рядовых сельских поселений). Количество крупных сельских поселений составляет 15 единиц (9\%), все они являются опорными центрами сельского расселения. 7 крупных опорных центров сельского расселения (почти половина всех таких сельских поселений в принятой генеральной совокупности) находится в пригородной зоне крупного города. Группа сельских поселений, пересекаемых республиканскими автомобильными дорогами общего пользования или с расположенными на их территории железнодорожными станциями и остановочными пунктами, насчитывает 55 единиц или $32 \%$ (33 опорных цента сельского расселения и 22 рядовых сельских поселения), однако лишь 6 из них находятся в пригородной зоне крупного города. 


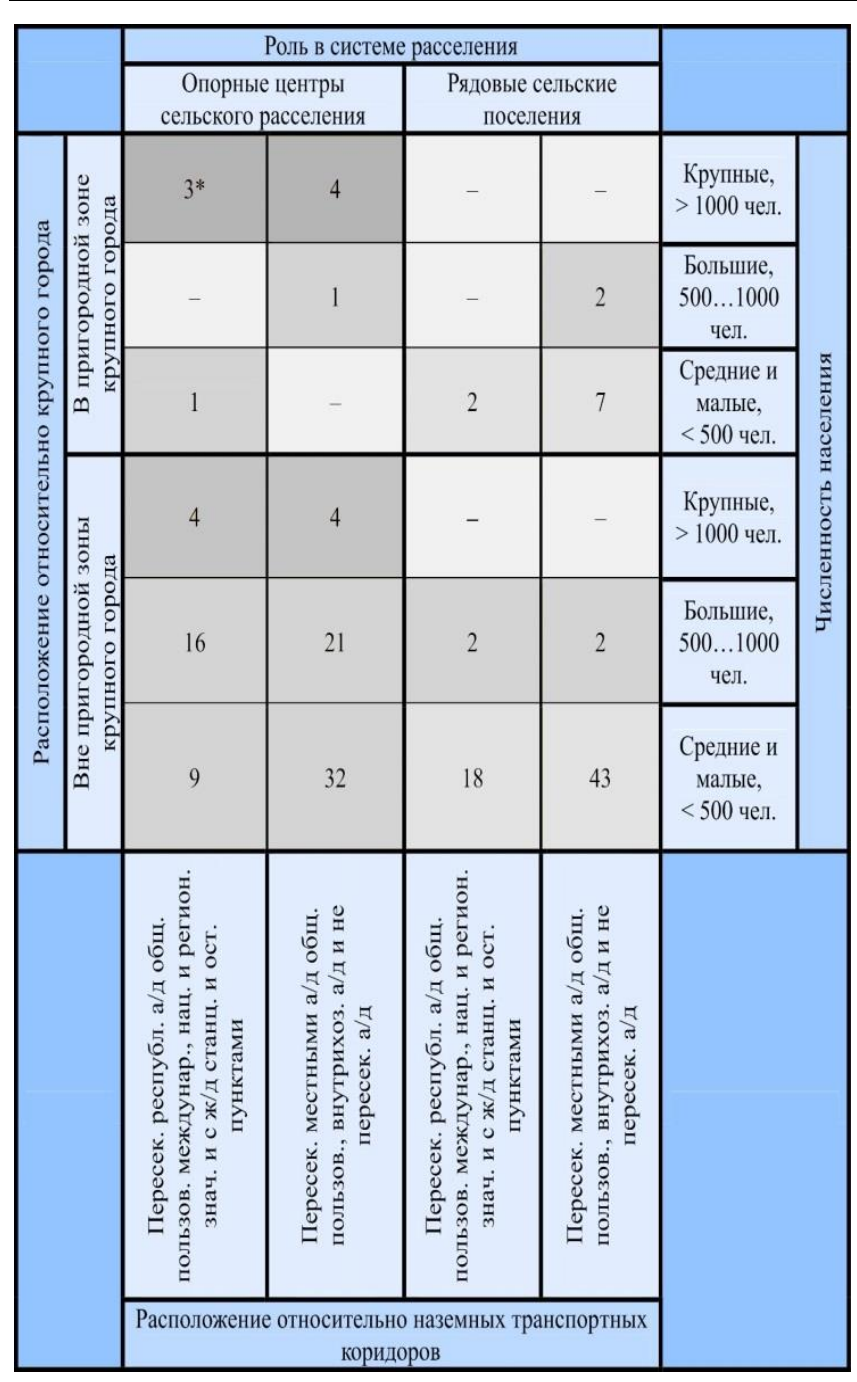

Рисунок 1 - Типологическая матрица (* - в ячейках приведено общее количество объектов исследования, обладающих соответствующей совокупностью признаков)

Наиболее представительной (43 единицы) оказалась группа рядовых сельских поселений с численностью населения менее 500 человек, расположенных вне пригородной зоны крупного города, пересекаемых местными автомобильными дорогами общего пользования, внутрихозяйственными автомобильными дорогами либо непересекаемые автомобильными дорогами. Минимально заполненными (по 1 объекту) оказались ячейки матрицы со следующими совокупностями типологических признаков объектов исследования: расположенные в пригородной зоне крупного города средние и большие опорные центры сельского расселения, соответственно пересекаемые и непересекаемые республиканскими автомобильными дорогами общего пользования, либо с расположенной или нерасположенной на их территории железнодорожной станцией или остановочным пунктом. В принятой генеральной совокупности не выявлены объекты исследования, обладающие следующими совокупностями типологических признаков: крупные рядовые сельские поселения; большие сельские поселения, расположенные в пригородной зоне крупного города, пересекаемые республиканскими автомобильными дорогами общего пользования либо с расположенной на их территории железнодорожной станцией или остановочным пунктом; средние по численности населения опорные центры сельского расселения, находящиеся в пригородной зоне крупного города, непересекаемые республиканскими автомобильными дорогами общего пользования или железной дорогой. Количество сельских поселений, расположенных в пригородной зоне г. Могилева, с численностью населения менее 1000 человек невелико (13 единиц). Обследование таких поселений не выявило значительных различий в организации архитектурного благоустройства по сравнению с соответствующими группами сельских поселений, расположенных вне пригородной зоны г. Могилева. Это позволяет объединить первые с последними в соответствующие определенным сочетаниям признаков группы объектов, независимо от их размещения относительно крупного города. Обследование больших рядовых сельских поселений также не выявило характерных различий в необходимом уровне архитектурного благоустройства по сравнению с опорными центрами сельского расселения. Этот факт в сочетании с малочисленностью больших рядовых сельских поселений позволяет сгруппировать их с опорными центрами сельского расселения, которым присущи соответствующие сочетания признаков. Идентична архитектурная среда больших и средних по численности населения опорных центров сельского расселения, расположенных вне пригородной зоны г. Могилева (аналогичны общественные и жилые территории), поэтому эти группы объектов исследования также можно объединить в зависимости от их расположения относительно наземных транспортных коридоров.

На основании результатов обследований сельских поселений и анализа распределения объектов генеральной совокупности по ячейкам типологической матрицы, для целей настоящего исследования выделено восемь характерных типов сельских поселений, отражающих возможные совокупности ведущих типологических признаков, которые оказывают влияние на архитектурное благоустройство селитебных территорий, в условиях Могилевской области (таблица 1). Для сельских поселений для каждого из выделенных типов характерно наличие соответствующей жилой застройки, общественных объектов, прочих территорий, улиц и дорог, железнодорожных станций или остановочных пунктов. Архитектурное благоустройство сельских поселений типов 1-А, 1-Б обладает внешними чертами благоустройства городских поселений. Благоустройство территории жилой застройки в сельских поселениях типов 1-А, 1-Б - преимущественно организованное, типов 2-А, 2-Б, 3-А, 3-Б - сочетает в себе самодеятельное и организованное, типов 4-А, 4-Б - преимущественно самодеятельное (за исключением улицы, совмещенной с транзитной республиканской автомобильной дорогой общего пользования, в сельских поселениях типа 4-Б). Полученная типология позволяет в дальнейшем определить рекомендации и требования к архитектурному благоустройству селитебных территорий сельских поселений с учетом дифференцированного подхода в зависимости от конкретного типа сельского поселения.

Применение метода типологизации может быть спроецировано и на другие регионы Беларуси. В процессе анализа остальных регионов могут быть выявлены их отличительные особенности, например, в Брестской области может оказать существенное влияние на распределение объектов исследования по ячейкам типологической матрицы разреженность и крупность сельских поселений, традиционное для системы расселения на территории западного Полесья, либо мелкоселенная система сельского расселения в Гродненской области, характерная для Понеманья. В Минской области может быть рассмотрен вопрос о выделении отдельного типа сельского поселения из-за расположения в зоне влияния единственного крупнейшего города Беларуси - г. Минска. Могут быть выявлены и другие особенности регионов, которые, впрочем, исходя из единых социально-экономических условий на территории Беларуси, к существенным отличиям от разработанной типологии, вероятнее всего, не приведут. 
Вестник Брестского государственного технического университета. 2021

Таблица 1 - Характеристика выделенных типов сельских поселений, отражающих возможные совокупности ведущих типологических признаков, которые оказывают влияние на архитектурное благоустройство селитебных территорий, в условиях Могилевской области

\begin{tabular}{|c|c|c|c|c|c|}
\hline $\begin{array}{c}\text { Типы } \\
\text { сельских } \\
\text { поселений }\end{array}$ & $\begin{array}{c}\text { Роль } \\
\text { в системе } \\
\text { расселения }\end{array}$ & $\begin{array}{c}\text { Численность } \\
\text { населения }\end{array}$ & $\begin{array}{c}\text { Расположение } \\
\text { относительно } \\
\text { крупного города }\end{array}$ & $\begin{array}{c}\text { Расположение } \\
\text { относительно наземных } \\
\text { транспортных коридоров }\end{array}$ & Примеры \\
\hline 1 & 2 & 3 & 4 & 5 & 6 \\
\hline Тип 1-А & $\begin{array}{l}\text { опорные центры } \\
\text { сельского } \\
\text { расселения }\end{array}$ & $\begin{array}{l}\text { крупные } \\
\text { (> } 1000 \text { чел.) }\end{array}$ & $\begin{array}{l}\text { в пригородной } \\
\text { зоне } \\
\text { крупного города }\end{array}$ & $\begin{array}{l}\text { не пересекаемые республиканскими автодо- } \\
\text { рогами общего пользования, без железнодо- } \\
\text { рожных станций и остановочных пунктов }\end{array}$ & $\begin{array}{l}\text { Вейно, Кадино } \\
\text { Могилевского района }\end{array}$ \\
\hline Тип 1-Б & $\begin{array}{l}\text { опорные центры } \\
\text { сельского } \\
\text { расселения }\end{array}$ & $\begin{array}{l}\text { крупные } \\
\text { (> } 1000 \text { чел.) }\end{array}$ & $\begin{array}{l}\text { в пригородной } \\
\text { зоне } \\
\text { крупного города }\end{array}$ & $\begin{array}{l}\text { пересекаемые республиканскими автодоро- } \\
\text { гами общего пользования, а также с желез- } \\
\text { нодорожными станциями или остановочными } \\
\text { пунктами }\end{array}$ & $\begin{array}{l}\text { Межисятки } \\
\text { Могилевского района }\end{array}$ \\
\hline Тип 2-A & $\begin{array}{l}\text { опорные центры } \\
\text { сельского } \\
\text { расселения }\end{array}$ & $\begin{array}{l}\text { крупные } \\
\text { (> } 1000 \text { чел.) }\end{array}$ & $\begin{array}{l}\text { вне пригородной } \\
\text { зоны крупного } \\
\text { города }\end{array}$ & $\begin{array}{l}\text { не пересекаемые республиканскими автодо- } \\
\text { рогами общего пользования, без железнодо- } \\
\text { рожных станций и остановочных пунктов }\end{array}$ & $\begin{array}{l}\text { Трилесино } \\
\text { Дрибинского, } \\
\text { Мышковичи } \\
\text { Кировского районов }\end{array}$ \\
\hline Тип 2-Б & $\begin{array}{l}\text { опорные центры } \\
\text { сельского } \\
\text { расселения }\end{array}$ & $\begin{array}{l}\text { крупные } \\
\text { (> } 1000 \text { чел.) }\end{array}$ & $\begin{array}{l}\text { вне пригородной } \\
\text { зоны крупного } \\
\text { города }\end{array}$ & $\begin{array}{l}\text { пересекаемые республиканскими автодоро- } \\
\text { гами общего пользования, а также с желез- } \\
\text { нодорожными станциями или остановочными } \\
\text { пунктами }\end{array}$ & $\begin{array}{l}\text { Вишов Белыничского, } \\
\text { Пудовня Дрибинского } \\
\text { районов }\end{array}$ \\
\hline \multirow{2}{*}{ Тип 3-A } & $\begin{array}{l}\text { опорные центры } \\
\text { сельского } \\
\text { расселения }\end{array}$ & $\begin{array}{l}\text { большие и средние } \\
\text { (100...1000 чел.) }\end{array}$ & \multirow{2}{*}{$\begin{array}{l}\text { в пригородной } \\
\text { зоне крупного } \\
\text { города и вне ее }\end{array}$} & \multirow{2}{*}{$\begin{array}{l}\text { не пересекаемые республиканскими } \\
\text { автодорогами общего пользования, } \\
\text { без железнодорожных станций } \\
\text { и остановочных пунктов }\end{array}$} & \multirow{2}{*}{$\begin{array}{l}\text { Овсянка Горецкого, } \\
\text { Фащевка Шкловского } \\
\text { районов }\end{array}$} \\
\hline & $\begin{array}{l}\text { рядовые } \\
\text { сельские } \\
\text { поселения }\end{array}$ & $\begin{array}{l}\text { большие } \\
\text { (500...1000 чел.) }\end{array}$ & & & \\
\hline \multirow{2}{*}{ Тип 3-Б } & $\begin{array}{l}\text { опорные центры } \\
\text { сельского } \\
\text { расселения }\end{array}$ & $\begin{array}{l}\text { большие и средние } \\
\text { (100...1000 чел.) }\end{array}$ & \multirow{2}{*}{$\begin{array}{l}\text { в пригородной } \\
\text { зоне крупного } \\
\text { города и вне ее }\end{array}$} & \multirow{2}{*}{$\begin{array}{l}\text { пересекаемые республиканскими } \\
\text { автодорогами общего пользования, } \\
\text { а также с железнодорожными станциями } \\
\text { или остановочными пунктами }\end{array}$} & \multirow{2}{*}{$\begin{array}{l}\text { Красная Буда } \\
\text { Кричевского, } \\
\text { Городище } \\
\text { Шкловского районов }\end{array}$} \\
\hline & $\begin{array}{l}\text { рядовые } \\
\text { сельские } \\
\text { поселения }\end{array}$ & $\begin{array}{l}\text { большие } \\
\text { (500...1000 чел.) }\end{array}$ & & & \\
\hline Тип 4-А & $\begin{array}{l}\text { рядовые } \\
\text { сельские } \\
\text { поселения }\end{array}$ & $\begin{array}{l}\text { средние и малые } \\
\text { (< } 500 \text { чел.) }\end{array}$ & $\begin{array}{l}\text { в пригородной } \\
\text { зоне крупного } \\
\text { города и вне ее }\end{array}$ & $\begin{array}{l}\text { не пересекаемые республиканскими автодо- } \\
\text { рогами общего пользования, без железнодо- } \\
\text { рожных станций и остановочных пунктов }\end{array}$ & $\begin{array}{l}\text { Тосна Горецкого, } \\
\text { Кищицы Дрибинского, } \\
\text { Колтово Мстиславского } \\
\text { районов }\end{array}$ \\
\hline Тип 4-Б & $\begin{array}{l}\text { рядовые } \\
\text { сельские } \\
\text { поселения }\end{array}$ & $\begin{array}{l}\text { средние и малые } \\
\text { (< } 500 \text { чел.) }\end{array}$ & $\begin{array}{l}\text { в пригородной } \\
\text { зоне крупного } \\
\text { города и вне ее }\end{array}$ & $\begin{array}{l}\text { пересекаемые республиканскими автодоро- } \\
\text { гами общего пользования, а также с желез- } \\
\text { нодорожными станциями или остановочными } \\
\text { пунктами }\end{array}$ & $\begin{array}{l}\text { Сеньково Горецкого, } \\
\text { Княжицы Шкловского, } \\
\text { Хоньковичи Чаусского } \\
\text { районов }\end{array}$ \\
\hline
\end{tabular}

\section{Заключение}

Таким образом, с применением метода типологизации определены ведущие типологические признаки, определяющие характерные особенности сельских поселений и оказывающие непосредственное влияние на формирование архитектурного благоустройства селитебных территорий, проведено сопоставление совокупности выделенных типологических признаков объектов исследования на основании построенной плоскостной сводной типологической матрицы, в результате анализа распределения объектов исследования по ячейкам которой выделено восемь типов сельских поселений, отражающих возможные совокупности ведущих типологических признаков, которые оказывают влияние на архитектурное благоустройство селитебных территорий. Метод типологизации позволяет устранить формализм в подходе к разработке практических рекомендаций по формированию и оптимизации архитектурного благоустройства селитебных территорий сельских поселений и повысить их ценность с учетом нынешних социально-экономических и социально-демографических условий Республики Беларусь, а разработанная типология сельских поселений является основой для разработки в дальнейшем ценных не только в научном, но и в практическом отношении структурно-графических моделей, стандартов архитектурного благоустройства и рекомендаций по его формированию при новом проектировании или оптимизации при реконструкции существующего благоустройства.

\section{Список цитированных источников}

1. Другомилов, Р. А. Учет социально-экономических, социальнодемографических и природно-экологических фракторов при совершенствовании архитектурного благоустройства поселений как способ повышения качества среды жизнедеятельности населения / Р. А. Другомилов // Экологическое состояние при- родной среды и научно-практические аспекты современных мелиоративных технологий : сб. науч. тр. / Российская акад. наук, Всероссийский науч.-исслед. ин-т гидротехники и мелиорации им. А. Н. Костякова (Мещерский филиал), Белорус. гос. с.-х. акад.; под общ. ред. Ю. А. Мажайского, В. И. Желязко. - Рязань, 2020. - Вып. 8/. - С. 279-283.

2. Градостроительство. Населенные пункты. Нормы планировки и застройки = Горадабудаўніцтва. Населеныя пункты. Нормы планіроўкі і забудовы: ТКП 45-3.01-116-2008*. - Введ. 01.07.09.Минск: М-во архитектуры и стр-ва Республики. Беларусь, 2018. $68 \mathrm{c}$.

\section{References}

1. Drugomilov, R. A. Accounting for socio-economic, socio-demographic and natural-environmental factors in improving the territory architectural accomplishment of settlements as a way to improve the quality of the living environment of the population / R. A. Drugomilov // Ecological state of the natural environment and scientific and practical aspects of modern land reclamation technologies: collection of scientific papers / Russian Academy of Sciences, All-Russian research Institute of hydraulic engineering and melioration named after A. N. Kostyakov (Meshchersk branch), Belarusian State Agricultural Academy; under the general editorship of Y. A. Mazhaysky, V. I. Zhelyazko. - Ryazan, 2020. - Issue 8 / - Pp. 279-283.

2. The urban development. Settlement. Standards of planning and building: TCP 45-3. 01-116-2008* - Put into effect on 01.07.09. Minsk: Ministry of architecture and construction of the Republic of Belarus, 2018. $-68 p$.

Материал поступил в редакцию 30.10.2020 